\title{
Mosquitos (Diptera, Culicidae) das regiões de Pendotiba e oceânica de Niterói (Rio de Janeiro, Brasil)
}

\author{
Alexandre Santos de Souza ${ }^{1}$ \\ Sebastião José de Oliveira ${ }^{2}$ \\ Márcia Souto Couri ${ }^{3}$
}

\begin{abstract}
Mosquitos (Diptera, Culicidae) of Pendotiba and oceanic regions of Niterói (Rio de Janeiro, Brazil). Female mosquitoes (Culicidae) were collected in human bait weekly between March 1997 to February 1998, in three different areas of the oceanic region of Niterói city, Rio de Janeiro State, in southeastern coast of Brazil. The results indicated the presence of 16 species: Anopheles aquasalis, Aedes scapularis, A. taeniorhynchus, A. albopictus, A. aegypti, Haemagogus leucocelaenus, Psorophora ferox, $P$. conffinis, $P$. cingulata, Culex quinquefasciatus, C. nigripalpus, Coquillettidia venezuelensis, Uranotaenia calosomata, Limatus durhami, Weyomyia oblita and Phoniomyia sp. A statistical analysis between monthly female frequencies and temperature, air humidity and precipitation monthly indices was done, using Sperman correlation in Statistica 4.2 program. The only difference among the collected points is the higher number of species collected in Engenho do Mato, in spite of the differences between them in relation to vegetal formation and conservation. The species showed higher frequencies of females during spring and summer seasons, and permit us to conclude that temperature and precipitation demonstrated high levels of correlation to female frequencies along the one year study, but the same was not observed in relation to air humidity. Some of the identified species, such as Aedes aegypti, A. albopictus, A. scapularis, Haemagogus leucocelaenus and Culex quinquefasciatus are important as disease vectors and control suggestions are made in front of the relative abundance of them in different periods of the year.

KEY WORDS. Diptera, Culicidae, ecology, Niterói, Rio de Janeiro
\end{abstract}

O Município de Niterói, no Estado do Rio de Janeiro, vem experimentando, desde a década de 80 , um acelerado crescimento populacional e econômico, devido não só ao crescimento autóctone, mas também à imigração proveniente do interior do Estado e de outros Municípios da Região Metropolitana do Rio de Janeiro. Esta imigração deve-se aos desequilíbrios na política de desenvolvimento regional, que faz com que o interior fique em desvantagem no processo de evolução econômica e ocasiona crise imobiliária na região metropolitana, resultante do fluxo do contingente humano. A falta de espaço residencial nas áreas mais tradicionais do município, bem como de outros municípios incluindo a própria capital (Rio de Janeiro),

1) Centro de Controle de Zoonoses, Prefeitura de Niterói. Bolsista da CAPES.

2) Coleção Entomológica, Fundação Instituto Oswaldo Cruz. Avenida Brasil 4365, 21045-900 Rio de Janeiro, Rio de Janeiro, Brasil.

3) Departamento de Entomologia, Museu Nacional. Quinta da Boa Vista, São Cristóvão, 20940-040 Rio de Janeiro, Rio de Janeiro, Brasil. Bolsista de Produtividade em Pesquisa (CNPq). 
tem levado à intensificação do processo de ocupação da região oceânica de Niterói, que também traz forte atividade comercial, principalmente de materiais de construção, padarias, supermercados, restaurantes, lanchonetes e lojas de artigos para animais. Estas atividades econômicas são reforçadas pelo grande afluxo de turistas que freqüentam as praias da região nos fins de semana e feriados, principalmente durante o verão, dando à região "status" de balneário.

Associados à expansão humana, estão os problemas ambientais, que são fatores decisivos no condicionamento da qualidade de vida, dentro da qual se insere preponderantemente a saúde pública. Devido ao desordenado processo de ocupação, a região sofre com várias deficiências estruturais, tais como coleta irregular de lixo, falta de rede de esgoto e de água tratada, terrenos abandonados que acumulam lixo e tornam-se focos de ratos e mosquitos, transporte deficiente, formação de favelas próximas a valões e rios contaminados de despejos domésticos e, por fim, deficiente rede pública de assistência médica.

Em meio a todos os problemas ambientais já citados, torna-se de especial relevância, em face das características da área em questão - a presença de culicídeos (Diptera, Culicidae) vetores de organismos causadores de doenças que, uma vez em contato com o atual contingente populacional, podem desencadear um quadro epidemiológico de proporções desconhecidas e cujo potencial carece de atenção e pesquisa por parte do poder público.

Os culicídeos são extremamente adaptados a muitos tipos de diferentes ambientes desde o intradomiciliar e outros ambientes artificiais urbanos e rurais até ambientes naturais variados como florestas, mangues e restingas, desde que haja local apropriado para sua reprodução e alimentação. Somente as fêmeas apresentam hábito hematófago, pois o sangue dos vertebrados são fonte de elementos importantes para a maturação de seus ovos, como compostos nitrogenados e ferro. Os machos em geral, alimentam-se de sucos vegetais e néctar.

A fecundação em geral ocorre não muito depois da emergência e logo a seguir, a fêmea está procurando alimento. Os ovos são colocados, dependendo da espécie, em diversos tipos de coleções d'água, que podem ser naturais como bromélias, ocos de árvores, alagados, lagos e poças temporárias, ou artificiais como pneus, caixas d'água, esgotos, cisternas, latas, garrafas e demais reservatórios que eventualmente surjam.

Os mosquitos constituem uma ameaça não apenas pela veiculação de patógenos de doenças, mas também pelo transtorno e incômodo que causam às pessoas, principalmente à noite quando perturbam inclusive o sono. Assim, causam prejuízos também com a queda de produtividade no trabalho.

Dentre os meios utilizados no combate, o mais amplamente empregado é o químico. Inicialmente com produtos inorgânicos e posteriormente, na década de 40, com inseticidas organoclorados como o DDT e posteriormente com os organofosforados, carbamatos e mais recentemente, com os piretróides. Normalmente eles são dispersados no ambiente na forma de "fog" aéreo (associado a algum óleo que auxilia na dispersão) ou na de UBV (ultra baixo volume) e atingem os insetos adultos durante o vôo, ou quando pousados em locais ao alcance do inseticida. É claro que este método afeta não só os mosquitos-alvo, como também espécies não nocivas que estejam no ambiente. Além disso, pode afetar ainda, pessoas e outros animais 
sensíveis que porventura recebam uma carga muito forte ou estejam em locais com pouca circulação de ar. As larvas são combatidas com o uso de Abate (Temefós), que está associado a grânulos de areia e é colocado em locais que venham a ser possíveis criadouros.

Tais inseticidas, embora eficazes no combate inicial, perdem eficácia com o tempo, ou pelo mal emprego, ou pela seleção de linhagens resistentes, o que obriga ao constante desenvolvimento de novos inseticidas.

O controle biológico tem se mostrado possivel e eficiente em certos casos, principalmente em populações de mosquitos na fase larvar. Peixes larvófagos, são particularmente interessantes nesse mecanismo, mostrando-se bastante eficientes. Bacillus thuringiensis israelensis também tem sido utilizado com sucesso em alguns países. No Brasil, por exemplo, no município de Niterói, uma equipe de pesquisadores de Cuba tem demonstrado a eficiência de uma cepa aplicada por eles no bairro de Jurujuba e na lagoa de Piratininga, embora nesta última seja desnecessário pela presença de peixes larvófagos em abundância, como foi constatado em observações pessoais durante os trabalhos de campo.

A região oceânica em estudo, há muito, já foi considerada como região endêmica para malária pois, além de contar com um ecossistema lagunar, é também caracterizada pela formação de restinga e mata atlântica. Principalmente na década de 40, o Departamento Nacional de Obras e Saneamento (DNOS) promoveu obras de drenagem da região afim de acabar com os alagados onde proliferavam os mosquitos que ameaçavam a saúde da população.

Embora a ocupação humana tenha alterado significativamente o ambiente, de modo que pouco restou das formações vegetais originais e o ecossistema lagunar também já não conserve suas características originais e esteja altamente poluído, muito do ecossistema primitivo ainda encontra-se preservado e em contato direto com a população humana. Forma-se assim um mosaico onde mata secundária, restinga, vegetação lagunar, mar, estradas, casas e turistas, se encontram e se permeiam.

Este conjunto de fatores motiva-nos então a averiguar que tipo de relação pode existir num ambiente perturbado, entre os vetores culicídeos e ser humano, na atual fase de transição da região.

Os objetivos desse trabalho são: identificar quais espécies de culicídeos encontram-se em convivência com a população humana, sua freqüência ao longo do ano e a influência da temperatura, precipitação pluviométrica, umidade relativa do ar e formação vegetal, sobre a flutuação populacional das espécies. Objetiva-se ainda, inferir possíveis conseqüências e riscos epidemiológicos decorrentes da situação atual e de um provável adensamento populacional humano nos anos subseqüentes, bem como a necessidade de combate durante o ano.

\section{HISTÓRICO}

Dentre os primeiros trabalhos de levantamentos com Culicidae publicados no Brasil, figuram os de Bourroul (1904) e GoEldi (1905), além da tese de A.G. Peryassú (1908), "Os culicídeos do Brasil". Vale, entretanto, ressaltar que no Rio de Janeiro, anterior ao trabalho em Culicidae de A.G. Peryassú (1908), é a descrição de uma espécie de Anopheles Meigen, 1818 de Sarapuí e Jardim Botânico por CRUZ 
(1901), em que o autor descreve ovo, larva e adulto fêmea, propondo provisoriamente o nome $A$. lutzi para o que pensava tratar-se de uma variedade de Anopheles (Nyssorhynchus) albitarsis Lynch-Arribálzaga, 1878, A. (Nyssorhynchus) argyritarsis Robineau-Desvoidy, 1827 ou A. (Nyssorhynchus) albimanus Wiedemann, 1821.

BourRoul (1904) descreveu inúmeras espécies brasileiras, em uma tese de 78 páginas.

GOELDI (1905) abordou a questão do papel dos mosquitos na saúde pública, propondo ações específicas. Resumiu as principais experiências sanitárias com Stegomyia fasciata (Fabricius, 1805) (atualmente Aedes (Stegomyia) aegypti (Linnaeus, 1762)) e Culex (Culex) pipiens fatigans Wiedemann, 1828, fez a exposição de aspectos biológicos de espécies autóctones e, especificamente com Stegomyia fasciata, relatou os conhecimentos então atualizados sobre esta espécie e a causa da febre amarela.

A.G. Peryassú (1908) na primeira tese do Instituto de Manguinhos (hoje Fundação Instituto Oswaldo Cruz), fez amplo tratado acerca da sistemática, classificação, biologia e distribuição geográfica dos culicídeos no Brasil e no Distrito Federal (Cidade do Rio de Janeiro), na qual mapeou a distribuição das espécies em cada rua da cidade do Rio de Janeiro de 1907.

CoutrinHo $(1942,1946 a, b, c, d, 1947)$ trouxe inúmeras contribuições ao conhecimento da fauna anofélica no Estado do Rio de Janeiro, com relação aos principais vetores de malária nas diversas regiões do Estado - A. (N.) darlingi, A. tarsimaculatus (= A. (Nyssorhynchus) aquasalis Curry, 1931) e A. (N.) albitarsis. Em 1947, quando estudou a distribuição dos anofelinos do Estado do Rio de Janeiro, explicitou para o município de Niterói a existência de focos endêmicos de malária, sendo que $A$. tarsimaculatus apresentou o maior nível de infecção natural. O autor pesquisou ainda o nível de infecção natural, distribuição e hábitos das espécies anofélicas, além de várias outras observações acerca da biologia de adultos e larvas.

DAVIS (1944a,b, 1945a,b) desenvolveu trabalhos relacionados à biologia e ecologia de mosquitos em áreas de mata, no município de Teresópolis, Rio de Janeiro, estudando preferências alimentares, ciclos anuais, tipos de habitat entre outros aspectos relacionados.

COUTINHO \& RICCIARDI (1945) estudaram a biologia e hábitos domiciliares de $A$. ( $N$.) darlingi em Campos, infecção natural e criadouros de larvas, confirmando o potencial da espécie como vetor da malária.

FERREIRA (1964) em um trabalho de âmbito nacional, estudou a distribuição dos anofelinos do Brasil, apontou para o Estado do Rio de Janeiro e antigo Estado da Guanabara a presença dos principais vetores anofélicos do Brasil - A. (N.) darlingi, A. (N.) aquasalis, A. (N.) albitarsis, A. (Kerteszia) cruzi Dyar \& Knab, 1908 e A. (Kerteszia) bellator Dyar \& Knab, 1906.

Na década de 70, BELKIN et al. (1971) fizeram um grande levantamento de espécies na América do sul, incluindo o Brasil, no qual descreveram algumas espécies novas. 
Na década de 80 trabalhos, como os de LourEnÇO-DE-Oliveira (1984), LOURENÇO-DE-OLIVEIRA et al. (1985), LOURENÇO-DE-OLIVEIRA \& SilVA (1985) e LOURENÇO-DE-OlIVEIRA \& HEYDEN (1986). Os autores estudaram aspectos da biologia dos Culicidae de uma área de planície em Jacarepaguá, como freqüência mensal, domiciliar, preferências horárias para hematofagia, entre outros.

GuimarÃEs \& ARlé (1984), GuimarÃes et al. (1985) e GuimarãEs \& VICTÓRIO (1986) descreveram também aspectos da biologia dos Culicidae no Parque Nacional da Serra dos Órgãos - distribuição estacional, vertical e preferência horária para hematofagismo.

GUIMARÃES et al. (1989), pesquisaram a freqüência intra, peri e extradomiciliar em áreas de mata atlântica em Itaguaí, demonstrando tendência de Aedes (Ochlerotatus) scapularis (Rondani, 1848) à domiciliação.

LABARTHE et al. (1998), na área da presente investigação, estudaram o comportamento e preferências alimentares do culicídeos e a transmissão de Dirofilaria immitis Raillet \& Henry, 1911 em Itacoatiara, região oceânica de Niterói, determinando Aedes (Ochlerotatus) taeniorhynchus Wiedemann, 1821, Culex (Culex) quinquefasciatus Say, 1823, Aedes (O.) scapularis, Culex (Culex) declarator Dyar \& Knab, 1906 e Culex (Culex) nigripalpus Theobald 1901, como os mais prováveis transmissores de dirofilaria para cães, podendo também transmitir a humanos.

\section{MATERIAL E MÉTODOS}

A coleta de adultos foi realizada em três locais distintos, com características geográficas diferentes, para fins de posterior comparação. Entretanto, tomou-se o cuidado de sempre manter proximidade de habitações humanas, de modo que se caracterizasse uma interface casa - ambiente natural.

As áreas de coleta, indicadas na figura 1, podem ser caracterizadas da seguinte maneira: Área 1: Cantagalo $\left(22^{\circ} 54^{\prime} \mathrm{S}\right.$; $\left.43^{\circ} 03^{\prime} \mathrm{W}\right)$ com floresta secundária recente próxima a residências, antiga plantação de bananeiras, em estágio sucessional ainda recente verificável pela presença de embaúbas, bananeiras, bambuzeiros e plantas de pequeno porte inclusive gramíneas. O terreno é fortemente inclinado. Área 2: Engenho do Mato (22 $56^{\prime} \mathrm{S} ; 43^{\circ} 00^{\prime} \mathrm{W}$ ) com floresta secundária em estágio sucessional mais adiantado que da área anterior, no pé da serra da Tiririca com presença de mata primária logo acima, subindo a encosta da serra. No local da coleta, passa um rio temporário que seca no inverno, outono e primavera, voltando a correr no verão. Presença de um reservatório que capta águas pluviais, a cerca de 80 metros do ponto de coleta, pertencente aos moradores do local, permanentemente semi-aberto. Área 3: Piratininga ( $22^{\circ} 56^{\prime} \mathrm{S} ; 43^{\circ} 05^{\prime} \mathrm{W}$ ) presença de restinga com complexo lagunar de água salobra, constituído de duas lagoas (Piratininga e de Itaipu) ligadas por canal retificado que recebe água doce de dois rios principais, atualmente muito poluídos. O local de coleta é entre residências e terrenos baldios cobertos de vegetação típica de restinga e próximo à lagoa de Piratininga. A vegetação da lagoa é variada com presença de inúmeras macrófitas inclusive taboa e gramíneas. 



Figs 1-2. (1) Mapa das localidades de coleta: Cantagalo, Piratininga e Engenho do Mato (Niterói, Rio de Janeiro); (2) espécies coletadas por ponto de coleta. 
As coletas foram realizadas semanalmente em cada um dos três pontos, de março de 1997 a fevereiro de 1998. Em cada ponto foram realizadas duas coletas de duas horas de duração cada. Uma à tarde, de 13 às $15 \mathrm{~h}$ (de 14 às $16 \mathrm{~h}$ no horário de verão) e outra crepuscular, que variou com o horário de verão e com a variação sazonal de início e fim do crepúsculo de 17 às 19 h até de 19 às 21 h, acompanhando o pôr do sol.

O método de captura à tarde consistia na coleta com o sugador, de todas as fêmeas que pousassem sobre o braço do coletor, que ficava parado em local sombreado esperando a chegada dos insetos para a hematofagia. A coleta crepuscular consistia, além do método de coleta à tarde supracitado, também de uma armadilha luminosa do tipo Shannon, para coletar também adultos machos, que facilitariam o trabalho de identificação.

A identificação do material foi feita com a utilização de microscópios ópticos e estereoscópicos, baseada em descrições e chaves dicotômicas da literatura especializada (LANE \& CERQUEIRA 1942; LANE 1953; ForATTINI 1965; CONSOLI \& LOURENÇO-DE-OLIVEIRA 1994). Isto foi feito a partir da morfologia externa, ou das dissecções das terminálias dos machos. Para as dissecações, foram utilizados os métodos tradicionais, com clarificação dos espécimes em fenol a $50 \%$, série alcoólica para desidratação e finalmente montava-se o material em lâmina com Euparal 3C 23S da Chroma-Gessellschaft, cobrindo com lamínula.

O material testemunho está depositado na coleção de Diptera do Museu Nacional, Rio de Janeiro (MNRJ).

Para a análise estatística, foi utilizada a correlação de Spearman, que forneceu os coeficientes de correlação $(R)$ entre as flutuações nas médias mensais de temperatura, precipitação e umidade relativa e as freqüências de mosquitos observadas em cada um dos pontos de coleta, utilizando-se o programa Statistica 4.2.

O R de Spearman é definido pela fórmula:

$$
R=1-6 \frac{\sum\left(y^{\prime}-x^{\prime}\right)^{2}}{n\left(n^{2}-1\right)}
$$

onde y' e x' são os postos da variáveis Y e X, (n) número de pares de dados. O coeficiente varia entre +1 (relação direta) e -1 (relação inversa). Para $R=0$, as duas variáveis são independentes. Para saber se R é significativamente diferente de zero, aplica-se um teste $t$ com n-2 graus de liberdade e/ou a tabela dos valores críticos de R para o nível de significância de 0,95 e 0,99 .

Os dados de precipitação, temperatura e umidade relativa utilizados na análise foram os fornecidos pelo Instituto Nacional de Meteorologia e provenientes da estação de Maricá, próxima ao local de coleta, constituindo médias mensais das médias diárias registradas.

Os dados da freqüência absoluta das fêmeas de cada ponto foram transformados em médias por hora de coleta, uma vez que algumas coletas tiveram um tempo menor que o planejado e algumas vezes os pontos tiveram números diferentes de coletas devido a percalços nas atividades de campo. Estas médias foram convertidas em médias de Williams ( $\log$ n-1) (WILliams 1937), para melhor visualização e tratamento dos dados nas correlações. 


\section{Características ecológicas das áreas de estudo}

A formação das lagoas de Itaipu e Piratininga deu-se pelo fechamento de antigas enseadas, ou visto de outra forma, pela evolução da formação da restinga que proporcionou a retificação do litoral suavizando as antigas reentrâncias produzidas pelos espigões que se projetavam no oceano (LAMEGO 1945).

A área possui a característica de ser abaciada (ou plana), resultante da convergência de leques de espraiamento ou da concentração de depósitos de enxurradas nas partes terminais de rampas de sedimentos, originando planícies de aluviões e depressões inundáveis com solos solodizados.

Quanto ao aspecto conservacionista, a região é dotada de erosões ativas sob a cobertura vegetal, numa faixa de intensidade de laminar ligeira-laminar moderada e em sulcos de erosão moderados, com um ligeiro movimento de massa.

Ocorre ainda, a erosão eólica severa a barlavento da Duna Grande, intensificada pela destruição da vegetação de sustentação da duna.

O clima da região, de acordo com a classificação de KÖEPPEN (1948), é do tipo AW, ou seja, quente e úmido com estação chuvosa no verão e seca no inverno. Este tipo climático ocorre em todo o município de Niterói (DRM 1981).

A precipitação pluviométrica anual no município de Niterói é de aproximadamente 1100 a $1300 \mathrm{~mm}$. A temperatura média é de $24^{\circ} \mathrm{C}$ (DRM 1981). O distrito de Itaipu não possui posto meteorológico, tornando a região mal servida de informações especificas (MME-DNAEE 1981).

As florestas de Mata Atlântica e restingas de Niterói foram diminuindo sua área de ocorrência, inicialmente para dar lugar à lavoura de cana-de-açúcar.

O cultivo de cana-de-açúcar, possivelmente, foi o primeiro de uma série de agentes que de alguma forma contribuíram para a descaracterização do ambiente.

Esta atividade foi substituída pelo café no decorrer do século XIX. Nesta época, Niterói possuía matas que forneciam toras que eram transformadas em carvão vegetal, fonte energética para as olarias instaladas no local.

Os cafezais que haviam avançado sobre os morros entraram em declínio no princípio do século XX, quando a mata iniciou um processo de regeneração natural originando matas secundárias, que persistem ainda hoje.

$\mathrm{Na}$ década de 40 iniciaram-se os loteamentos das terras particulares, que deram continuidade aos desmatamentos. Este processo inicial de ocupação intensificou não só o desmatamento, mas gerou alterações na flora e fauna.

A Serra da Tiririca, hoje, apesar de se encontrar em melhores condições de preservação, apresenta em algumas áreas cobertura vegetal secundária, mas também remanescentes da vegetação da Mata Atlântica original. As populações de orquídeas e a fauna nativa vêm sendo reduzidas em função da coleta e caça predatórias e das queimadas. Há também de se destacar a substituição da mata pelo cultivo de banana nesse ambiente.

Nas baixadas, o desmatamento abriu espaço para a urbanização. Espécies como o vinhático (Plathymenia foliolosa Benth., 1841) e o pau-brasil (Caesalpinia echinata Lam., 1785) já não são mais encontradas. Os ecossistemas outrora dominados pelas duas espécies citadas foram substituídos por vegetação arbustiva residual característica das áreas urbanizadas ou por gramíneas invasoras (BARRoso et al. 1993; ECP 1979). 
A vegetação costeira representada pelos tipos de restingas - de praia, de dunas e perilagunar - foi praticamente toda substituída por áreas terraplenadas. Muitas das espécies que ocorriam nesses biomas devem ter sido muito importantes para a economia indígena. A pesquisa sobre o potencial econômico de muitas espécies da flora nativa ficarão desconhecidas da civilização devido ao seu desaparecimento.

A vegetação perilagunar era bastante extensa, constituída de alagados, brejos e banhados contribuintes importantes no ciclo ecológico das lagunas. Estes sistemas atuam retendo sedimentos trazidos pelos rios e servindo de habitat para peixes e camarões jovens (pós-larvas) Este tipo de vegetação encontra-se profundamente modificado devido à drenagem e aos aterros, que favoreceram a expansão urbana. Em relação à flora destaca-se o predomínio de taboa (Typha dominguensis Pers., 1807) associada a gramíneas e ciperáceas.

$\mathrm{O}$ que ainda existe da flora da restinga são alguns remanescentes na margem oeste da laguna de Itaipu. Já se pode afirmar que o ecossistema da restinga foi praticamente erradicado (ARAÚJo \& VILAÇA 1981). Antes do uso de terraplanagem nessas áreas, o solo pouco fértil das restingas impedia seu uso agrícola, preservando-a da devastação.

Atualmente, devido à abertura do canal da lagoa de Itaipu em 1978, pode-se encontrar, nas margens dessa lagoa, duas espécies características de mangue, Avicennia schaueriana Stapf \& Leechm. Ex. Moldenke, 1939 e Laguncularia racemosa (L.) C.F. Gaertn., 1807.

O Morro das Andorinhas apresenta uma vegetação pioneira que se desenvolve sobre afloramentos rochosos à beira-mar. As matas revestem os topos e as depressões. Apresenta ainda, uma vegetação extremamente variada quanto ao seu estado de preservação. As árvores são bem desenvolvidas, com alturas que variam entre 12 e 15 metros. O morro das Andorinhas tem aproximadamente $200 \mathrm{~m}$ de altitude em seu ponto culminante, que se encontra voltado para o mar e próximo a ele.

Os incêndios florestais têm modificado muito a vegetação em alguns locais. A cobertura vegetal tem-se mostrado de diversas formas variando entre capoeira e vegetação rasteira. Ocorre ainda, em quantidade menor, o capim colonião (Panicum maximım Jacq., 1781), espécie invasora africana que facilita a ação do fogo em razão de sua fácil combustão nos meses de inverno, nos quais as chuvas escasseiam.

Outro fator modificador da cobertura vegetal tem sido a exploração humana em busca de lenha e espécies ornamentais, além da ocupação habitacional irregular que intensificou-se nas duas últimas décadas.

\section{RESULTADOS}

As espécies constatadas nos três locais investigados são listadas a seguir e estão representadas na figura 2 .

Área 1 (Cantagalo), dez espécies: Aedes aegypti (Linnaeus, 1722); Aedes albopictus Skuse, 1894; Aedes scapularis (Rondani, 1848); Aedes taeniorhynchus (Wiedemann, 1821); Haemagogus leucocelaenus Dyar \& Shannon, 1924; Psorophora cingulata Fabricius, 1905; Culex quinquefasciatus Say, 1823; Limatus durhami Theobald, 1901; Weyomyia oblita (Lutz, 1905) e Phoniomyia sp. 
Área 2 (Engenho do Mato), doze espécies: Aedes albopictus; Aedes scapularis; Aedes taeniorhynchus; Haemagogus leucocelaenus; Culex nigripalpus Theobald, 1901; Psorophora (Janthinosoma) ferox Von Humboldt, 1819; Psorophora (Grabhamia) confinnis (Arribálzaga, 1891); Coquillettidia venezuelensis (Theobald, 1912); Uranotaenia calosomata Dyar \& Knab, 1907; Limatus durhami; Phoniomyia sp. e Weyomyia oblita.

Área 3 (Piratininga), oito espécies: Aedes albopictus; Aedes aegypti; Aedes scapularis; Aedes taeniorhiynchus; Culex nigripalpus; Culex quinquefasciatus; Anopheles aquasalis Curry, 1932 e Limatus durhami.

As informações acima estão resumidas na tabela I e são provenientes das coletas em isca humana e da armadilha luminosa.

Tabela I. Espécies de culicideos encontradas nos três pontos de coleta (Cantagalo, Piratininga e Engenho do Mato) em Niterói, Rio de Janeiro, de março de 1997 a fevereiro de 1998.

\begin{tabular}{|c|c|c|c|}
\hline Espécie & Cantagalo & Piratininga & Engenho do Mato \\
\hline Anopheles aquasalis & - & $x$ & - \\
\hline Culex nigripalpus & - & $x$ & $\mathrm{x}$ \\
\hline Culex quinquefasciatus & $\mathrm{x}$ & $x$ & - \\
\hline Aedes aegypti & $x$ & $x$ & - \\
\hline Aedes albopictus & $\mathrm{x}$ & $\mathrm{x}$ & $\mathrm{x}$ \\
\hline Aedes scapularis & $x$ & $x$ & $x$ \\
\hline Aedes taeniorrhynchus & $x$ & $x$ & $\mathrm{x}$ \\
\hline Haemagogus leucocelaenus & $x$ & - & $x$ \\
\hline Psorophora cingulata & $x$ & - & - \\
\hline Psorophora confinnis & - & - & $\mathrm{x}$ \\
\hline Psorophora ferox & - & - & $\mathrm{x}$ \\
\hline Coquillettidia venezuelensis & - & - & $\mathrm{x}$ \\
\hline Uranotaenia calosomata & - & - & $x$ \\
\hline Limatus durhami & $x$ & $x$ & $\mathrm{x}$ \\
\hline Wyeomyia oblita & $x$ & - & $\mathrm{x}$ \\
\hline Phoniomyia sp. & $x$ & - & $x$ \\
\hline
\end{tabular}

Anopheles (Nyssorhynchus) aquasalis Curry, 1932 foi o único representante da sub-família Anophelinae coletado. Esta espécie reproduz-se em reservatórios temporários de águas salobras mais comuns no litoral, e durante o período chuvoso. Em virtude dessa dependência, escasseiam no período seco, e voltam a ser abundantes no período das chuvas. São comumente exófilos, zoofílicos e essencialmente crepusculares. É considerado um dos vetores primários de malária, no Norte e Nordeste do Brasil.

Todas as demais espécies coletadas pertencem à sub-família Culicinae. Da tribo Culicini, Culex (Culex) nigripalpus Theobald, 1901 e Culex (Culex) quinquefasciatus Say, 1823; o primeiro é transmissor de encefalites nos EUA, Trinidad e Jamaica, enauanto o segundo, é um mosquito essencialmente urbano, encontrado dentro das residências ou no peridomicílio. É o vetor primário da filariose bancroftiana no Brasil.

Da tribo Sabethini, Limatus durhami Theobald, 1901 e Wyeomyia (Wyeomyia) oblita (Lutz, 1905) foram capturadas. Nenhuma das duas espécies têm preferência pelo homem e embora não sejam importantes vetores de doenças, estão implicada na transmissão de arboviroses ao homem. 
Todas as demais espécies pertencem á tribo Aedini. Entre as espécies de Aedes, A. (Stegomyia) aegypti (Linnaeus, 1762) é o principal vetor de dengue e febre amarela urbana no Brasil. A. (Ochlerotatus) taeniorhynchus (Wiedemann, 1821) juntamente com $A$. (Ochlerotatus) scapularis (Rondani, 1848) são os principais transmissores de Dirofilaria immitis na região de Itacoatiara, próxima à área estudada (CONSOl \& LOURENÇO-DE-Oliveira 1994; LABARTHE et al. 1998). Ainda de importância na transmissão de patógenos no Brasil, destaca-se a espécie Haemagogus (Conopostegus) leucocelaenus Dyar \& Shannon, 1924, importante vetor do vírus da febre amarela silvestre (CAUSEY et al. 1950).

Pode-se observar, através da leitura dos gráficos, (Figs 3-11), que em todos os três pontos de coleta há maior freqüência de indivíduos de todas as espécies nas coletas realizadas na época mais quente e de maiores índices pluviométricos do ano, que se dá nos meses de verão (dezembro, janeiro e fevereiro, tabelas II-IV). Para análise da freqüência dos mosquitos, foram consideradas apenas as fêmeas, por terem tido uma freqüência significativa nas coletas, o que não aconteceu com os machos.

As espécies do gênero Culex (considerando em conjunto as fêmeas de $C$. quinquefasciatus e principalmente C. nigiripalpus), Aedes scapularis, Aedes albopictus, Aedes aegypti e Phoniomyia sp. foram coletadas ao longo de todo o ano, sofrendo entretanto, uma baixa sensivel nos meses de pouca chuva, enquanto outras espécies praticamente não foram capturadas no mesmo período. Anopheles aquasalis entretanto, apesar de raro nessa época, foi capturado após chuvas moderadamente fortes, fenômeno que foi escasso em 1997, de acordo com os efeitos climáticos freqüentemente atribuídos ao "El Niño" sobre o Brasil nesse ano. Convém ressaltar que o mês em que foram capturados em maior número, foi justamente o de novembro e não no período de dezembro a fevereiro (Tab. IV).

Em todos os pontos de coleta, A. scapularis foi a espécie mais abundante, perfazendo $82,5 \%, 82 \%$ e $71 \%$ do total de espécimes coletados no Engenho do Mato, Cantagalo e Piratininga respectivamente. As demais espécies apresentaram percentual bem mais baixo. Em Piratininga, Aedes taeniorhynchus também apresenta presença expressiva, perfazendo $20,7 \%$ do total de espécimes coletados. Em função da baixa exofilia (RACHOU et al. 1958; DEANE 1951) Culex quinquefasciatus foi colocado junto com $C$. nigripalpus, sendo que ambos foram bem menos expressivos que as espécies de Aedes, embora apresentando-se mais expressivamente em Engenho do Mato (Tab. II).

A correlação de Spearman deu uma ordem dos valores do coeficiente de correlação $(\mathrm{R})$ correlacionando temperatura, umidade relativa do ar e precipitação pluviométrica com a freqüência em função deles (Tab. VI). Dentre os fatores, o único que não apresentou correlação significativa com a freqüência de mosquitos foi a umidade relativa. É fácil entender este fato, uma vez que este fator apresentou uma pequena variação ao longo do período coletado, apresentando médias sempre acima de $70 \%$ ao longo de todo o ano (Tab. V) enquanto a freqüência mostrou variação significativa no mesmo período (Figs 3-5), certamente em função dos outros fatores. 


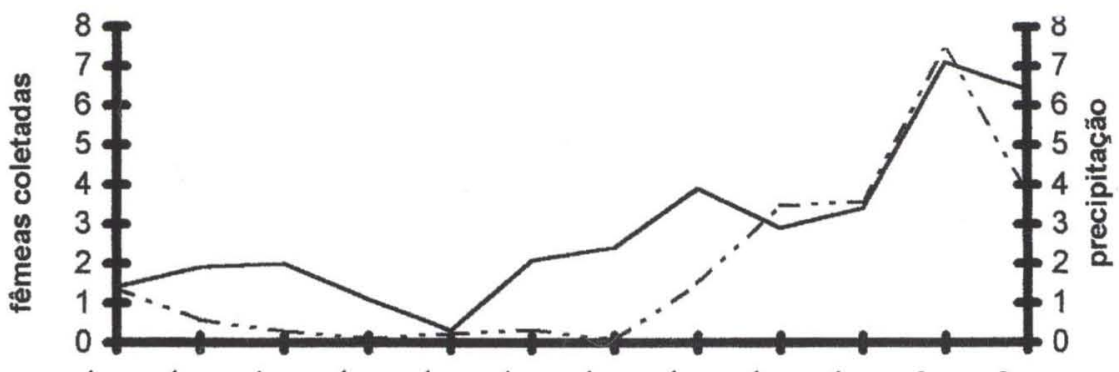

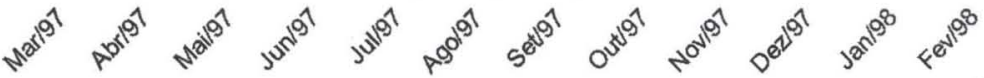
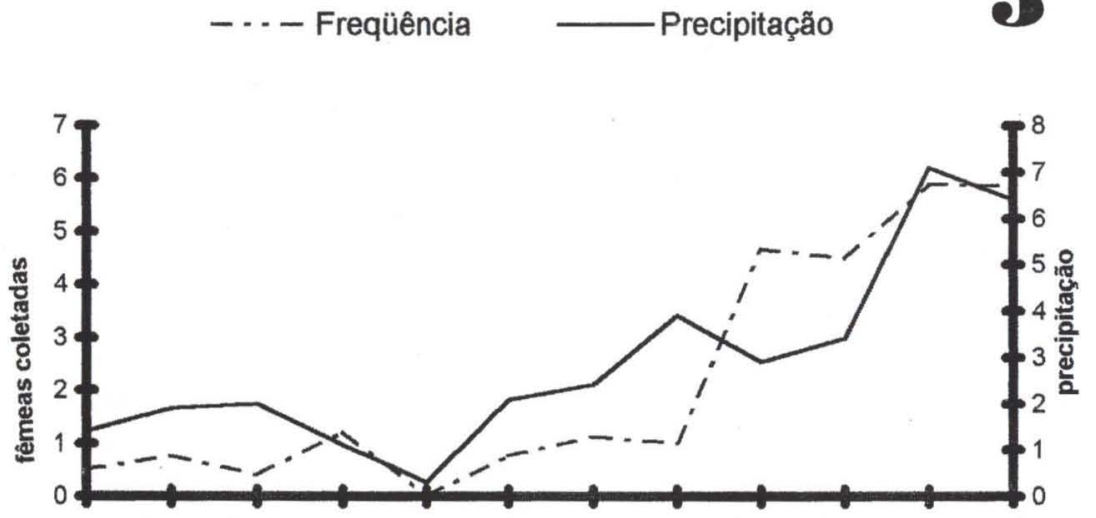

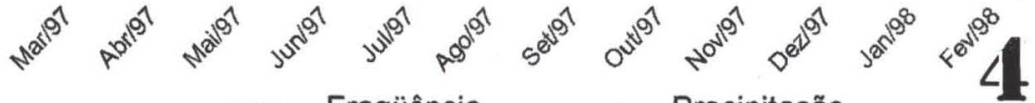

- - - Freqüência Precipitação

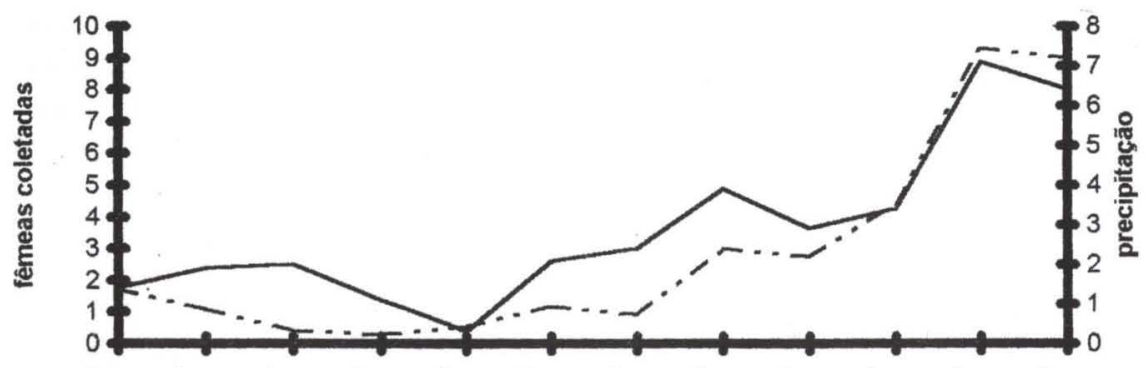

रूकी

$$
\text { - - - Freqüência }
$$

Precipitação



Figs 3-5. Freqüência (média de Williams) de fêmeas coletadas em Niterói, Rio de Janeiro, e médias de precipitação em: (3) Cantagalo, (4) Piratininga; (5) Engenho do Mato. 

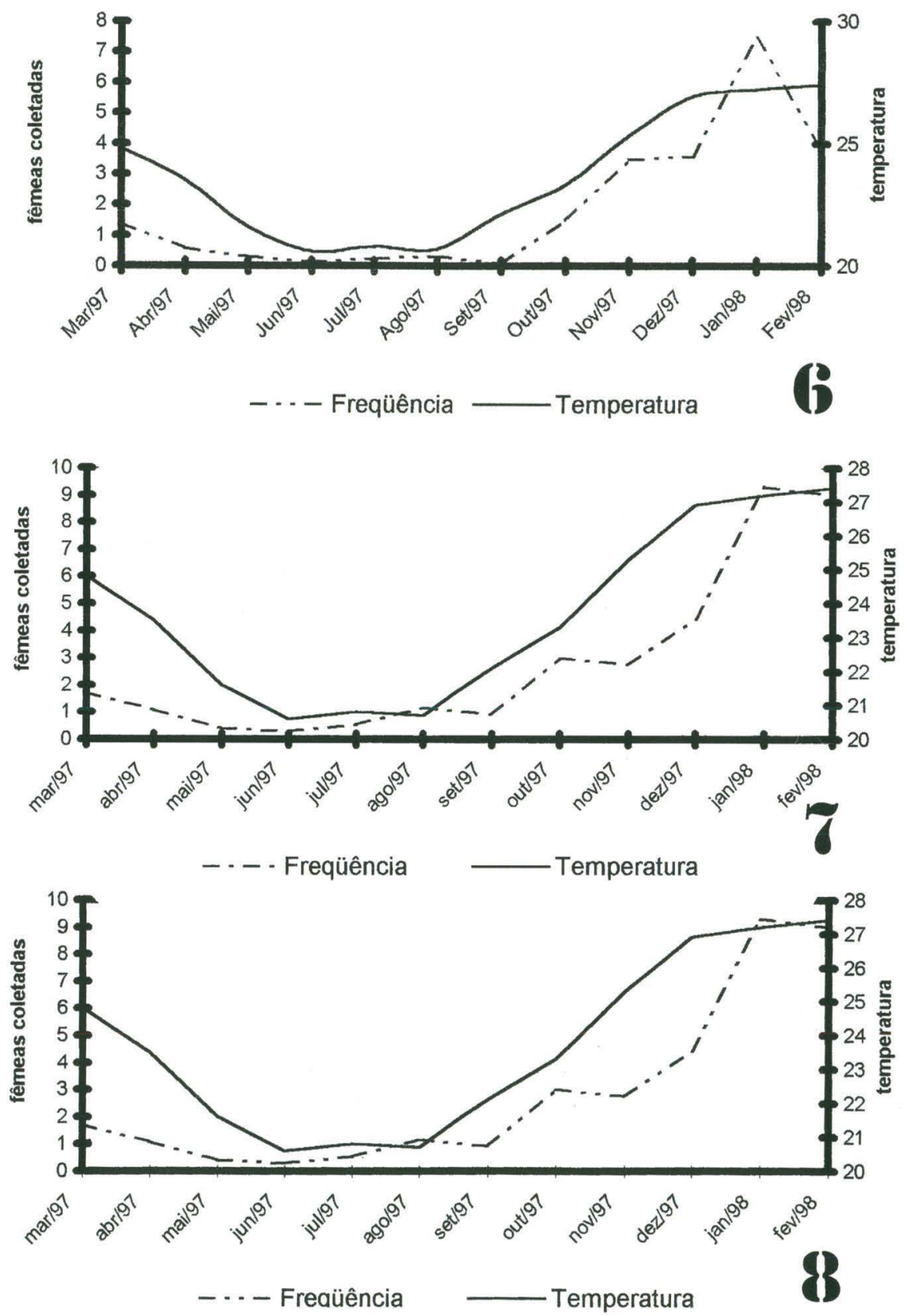

Figs 6-8. Freqüência (média de Williams) de fêmeas coletadas, Rio de Janeiro, e médias de temperatura em: (6) Cantagalo; (7) Piratininga; (8) Engenho do Mato. 


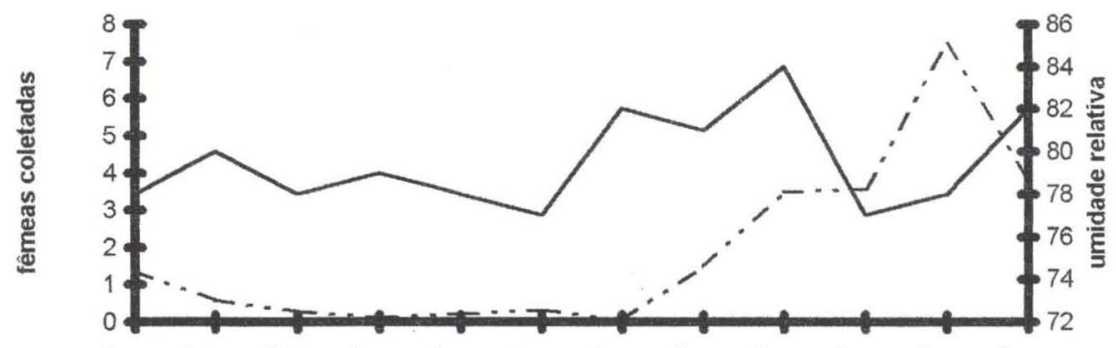

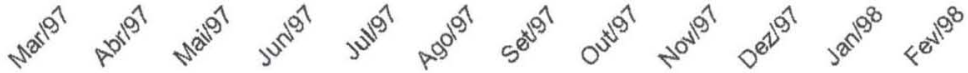

- - - Freqüência U Umidade Relativa



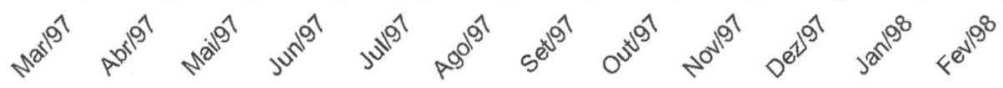
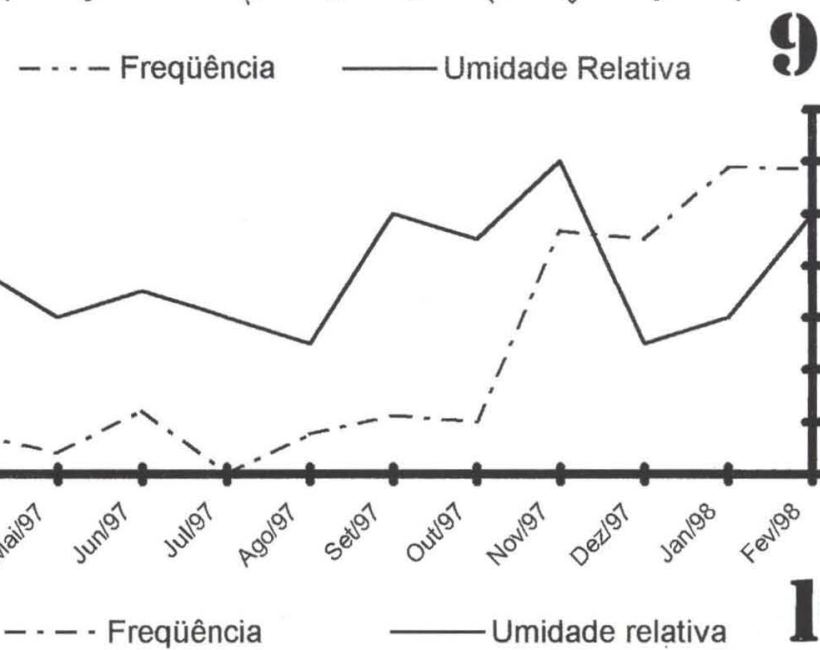
Umidade relativa
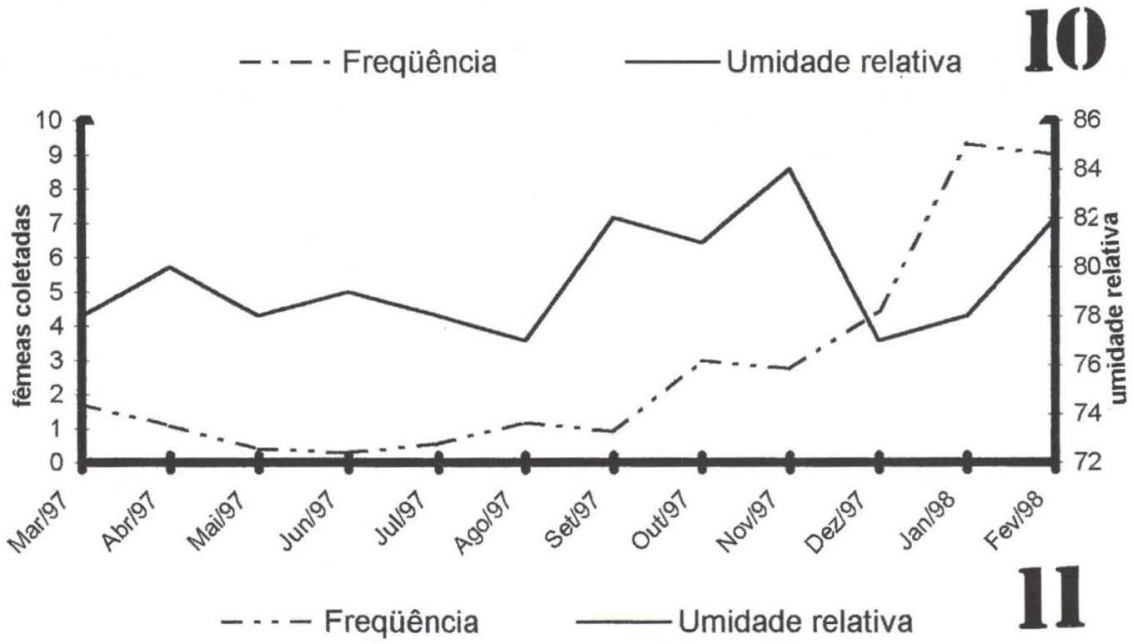

Figs 9-11. Freqüência (média de Williams) de fêmeas coletadas, Rio de Janeiro, e médias de umidade relativa em: (9) Cantagalo; (10) Piratininga; (11) Engenho do Mato. 
Tabela II. Freqüência mensal absoluta de culicídeos fêmeas, coletados no Engenho do Mato, Niterói, Rio de Janeiro, de março de 1997 a fevereiro de 1998.

\begin{tabular}{|c|c|c|c|c|c|c|c|c|c|c|c|c|c|c|}
\hline \multirow{2}{*}{ Espécie } & \multicolumn{10}{|c|}{ Ano de 1997} & \multicolumn{4}{|c|}{ Ano de 1998} \\
\hline & Mar & $\mathrm{Abr}$ & Mai & Jun & Jul & Ago & Set & Out & Nov & Dez & Jan & Fev & Total & $\%$ \\
\hline Culex sp. & 8 & 10 & 1 & & & & & & & & 87 & 24 & 130 & 5,5 \\
\hline Aedes albopictus & 2 & & & 3 & 1 & & 3 & 6 & 4 & 3 & 7 & 38 & 67 & 2,9 \\
\hline Aedes scapularis & 2 & 8 & 2 & 1 & & 16 & 5 & 65 & 34 & 301 & 847 & 657 & 1938 & 82,5 \\
\hline Aedes taeniorrhynchus & 8 & & 4 & & & & & & & 2 & 6 & 7 & 27 & 1,1 \\
\hline Haemagogus leucocelaenus & & & & & & & & 26 & 11 & 3 & 1 & 13 & 54 & 2,3 \\
\hline Psorophora ferox & & & & & & & & & & & 5 & 5 & 10 & 0,4 \\
\hline Psorophora connfinis & & 2 & & & & & & & & & & & 2 & 0,1 \\
\hline Limatus durhami & 1 & & & & 1 & & & & 11 & 2 & & & 15 & 0,6 \\
\hline Phoniomyia sp. & & & & 1 & 7 & 8 & 7 & 6 & 3 & 22 & 8 & 23 & 87 & 3,7 \\
\hline Wyeomyia oblita & & & & & 1 & & & & 3 & & & & 4 & 0,2 \\
\hline Uranotaenia calosomata & & 1 & & & & & & & & & & & 1 & - \\
\hline Coquillettidia venezuelensis & 13 & & & & & & & & & & & 1 & 14 & 0,6 \\
\hline
\end{tabular}

Tabela III. Freqüência mensal absoluta de culicídeos fêmeas, coletados em Cantagalo, Niterói, Rio de Janeiro, de março de 1997 a fevereiro de 1998.

\begin{tabular}{|c|c|c|c|c|c|c|c|c|c|c|c|c|c|c|}
\hline \multirow{2}{*}{ Espécie } & \multicolumn{10}{|c|}{ Ano de 1997} & \multicolumn{4}{|c|}{ Ano de 1998} \\
\hline & Mar & $\mathrm{Abr}$ & Mai & Jun & Jul & Ago & Set & Out & Nov & Dez & Jan & Fev & Total & $\%$ \\
\hline Culex sp. & & & & & & & & & & & & 1 & 1 & 0.1 \\
\hline Aedes aegypti & 4 & 2 & 3 & 2 & & 1 & & 2 & 4 & 1 & & & 19 & 1,8 \\
\hline Aedes scapularis & 3 & 2 & & & 1 & 5 & & 18 & 75 & 40 & 560 & 139 & 843 & 82,0 \\
\hline Aedes albopictus & 1 & 8 & 1 & & 3 & & 1 & 3 & 6 & 11 & 18 & 6 & 58 & 5,6 \\
\hline Aedes taeniorrhynchus & 1 & & & & & & & & 2 & & 27 & 5 & 35 & 3,4 \\
\hline Limatus durhami & 8 & & & & & & & 2 & 5 & 12 & 14 & 1 & 42 & 4,1 \\
\hline Phoniomyia sp. & & 1 & & & & & & 1 & 6 & 4 & 5 & 2 & 19 & 1.8 \\
\hline Wyeomyia oblita & 1 & & 1 & & & 1 & & 1 & & & 1 & 3 & 8 & 0,8 \\
\hline Psorophora cingulata & & & & & & & & & 2 & & 1 & & 2 & 0.2 \\
\hline Haemagogus leucocelaenus & & & & & & & & & & & & & 1 & 0,1 \\
\hline
\end{tabular}

Tabela IV. Freqüência mensal absoluta de culicídeos fêmeas, coletados em Piratininga, Niterói, Rio de Janeiro, de março de 1997 a fevereiro de 1998.

\begin{tabular}{|c|c|c|c|c|c|c|c|c|c|c|c|c|c|c|}
\hline \multirow{2}{*}{ Espécie } & \multicolumn{10}{|c|}{ Ano de 1997} & \multicolumn{4}{|c|}{ Ano de 1998} \\
\hline & Mar & $\mathrm{Abr}$ & Mai & Jun & Jul & Ago & Set & Out & Nov & Dez & Jan & Fev & Total & $\%$ \\
\hline Anopheles aquasalis & 4 & & & 1 & & & & & 14 & 3 & 3 & 3 & 28 & 1,9 \\
\hline Culex sp. & 6 & 4 & 2 & 16 & & 4 & 5 & 7 & 84 & 184 & 338 & 2 & 9 & 0,6 \\
\hline Aedes scapularis & & 1 & 2 & 6 & & 7 & 9 & 8 & 5 & 9 & 8 & 360 & 1010 & 71,0 \\
\hline Aedes albopictus & & 1 & & 4 & & & 4 & 2 & 64 & 39 & 134 & 11 & 66 & 4,6 \\
\hline Aedes taeniorhynchus & & & & & & & & & & & & 47 & 295 & 20.7 \\
\hline Limatus durhami & & & & & & 1 & 1 & 2 & 6 & 2 & & & 13 & 0,9 \\
\hline Aedes aegypti & 1 & 2 & & & & 2 & & & & & & & 5 & 0,3 \\
\hline
\end{tabular}

As relações entre freqüência e precipitação apresentam um elevado $\mathrm{R}$, (Tab. VI), o que representa que, certamente, a precipitação tem alta correlação com a abundância de mosquitos nas três áreas estudadas. O mesmo acontece com a temperatura, na qual o R e o nível de significância são elevados em todos os pontos, também apontando para uma alta correlação entre este fator e a abundância dos mosquitos. A temperatura comporta-se de modo a apresentar uma elevação no início 
e no final do ano (Tab. V) em que é subitamente acompanhada por um pico na freqüência de insetos (Tabs II-IV) o mesmo acontecendo com a precipitação, de forma ainda mais perceptível (Tab. V).

Tabela V. Médias mensais de precipitação $(\mathrm{mm})$, temperatura $\left({ }^{\circ} \mathrm{C}\right)$ e umidade relativa $(\%)$ da estação de Maricá, Rio de Janeiro, de março de 1997 a fevereiro de 1998 (dados do Instituto Nacional de Meteorologia).

\begin{tabular}{lccc}
\hline Meses & Precipitaçằ & Temperatura & Umidade relativa do ar \\
\hline Março & 1,4 & 24,8 & 78 \\
Abril & 1,9 & 23,5 & 80 \\
Maio & 2,0 & 21,6 & 78 \\
Junho & 1,1 & 20,6 & 79 \\
Julho & 0,3 & 20,8 & 78 \\
Agosto & 5,2 & 20,7 & 77 \\
Setetembro & 2,4 & 22,1 & 82 \\
Outubro & 3,9 & 23,3 & 81 \\
Novembro & 2,9 & 25,3 & 84 \\
Dezembro & 3,4 & 26,9 & 77 \\
Janeiro/1998 & 7,1 & 27,2 & 78 \\
Fevereiro & 6,4 & 27,4 & 82 \\
\hline
\end{tabular}

Esta correlação reflete-se, de forma visível, na própria curva apresentada por estes dois fatores, onde nota-se uma tendência de aumento de valor à medida em que se aproximam os meses de dezembro, janeiro e fevereiro, mesma tendência observada na freqüência de mosquitos, particularmente com a curva de precipitação (Figs 3-5).

Com base nos dados da tabela VI, observa-se entretanto, que embora precipitação e temperatura tenham praticamente o mesmo peso a julgar pelos valores de R no Engenho do Mato e Cantagalo, o mesmo não ocorre em Piratininga, onde a temperatura apresenta um $\mathrm{R}$ mais significativo do que o da precipitação. Vale ressaltar que os dois primeiros são locais de mata, enquanto o último, pela de restinga, o que pode explicar a diferença, uma vez que na restinga a evaporação da água das poças no solo é mais rápida e as espécies dispõem de outros criadouros além delas como as poças no domínio das rochas da praia.

Tabela VI. Correlações ( $\mathbf{R}$ de Spearman) entre precipitação, temperatura, umidade relativa do ar e a freqüência de fêmeas coletadas em cada ponto de coleta (Cantagalo, Piratininga e Engenho do Mato) em Niterói, Rio de Janeiro, de março de 1997 a fevereiro de 1998.

\begin{tabular}{lccc}
\hline \multicolumn{1}{c}{ Local de coleta } & Precipitação & Temperatura & Umiade relativa do ar \\
\hline Engenho do Mato & $0,804(p=0,001)$ & $0,867(p=0,0020)$ & $0,046(p=0,886)$ \\
Cantagalo & $0,706(p=0,010)$ & $0,881(p=0,0001)$ & $0,003(p=0,991)$ \\
\hline
\end{tabular}

\section{DISCUSSÃO}

A presença das espécies coletadas coincide com a faixa de distribuição já descrita para as mesmas em trabalhos anteriores (FORATTINI 1965; CONSOLI et al. 1994); porém, a composição delas apresenta variações entre os pontos de coleta. Assim algumas espécies como Aedes scapularis, A. albopictus e A. taeniorhynchus, 
são encontradas em todos os pontos apresentando ainda as maiores freqüências relativas entre as demais, assim como Limatus durhami e Phoniomyia sp., só que em freqüências menos expressivas (Tabs I-IV). Este domínio evidencia a adaptabilidade dessas espécies, particularmente $A$. scapularis a ambientes alterados pelo homem (ForATINI et al. 1978a, 1995; DoRVILLÉ 1996), tanto quanto àqueles não tão alterados, e também a capacidade de habitarem ambientes tão diferentes quanto mata e restinga.

Se comparada a freqüência relativa dessas espécies em cada ponto, nota-se claramente a predominância de $A$. scapularis em todos os pontos (Tabs II-IV). Esta espécie tem rápido desenvolvimento em áreas alagáveis durante épocas de chuvas fortes, pois deposita seus ovos em folhas de plantas desse tipo de ambiente, os quais são submersos, daí eclodindo as larvas. Este parece ser o caso principalmente de Piratininga, embora nas outras duas áreas existam locais com essas características.

A área de Engenho do Mato, apresentou maior variedade de espécies coletadas (Tab. I), possivelmente em função de ser a mais preservada do ponto de vista ambiental. Embora as coletas tenham sido realizadas em faixa de mata secundária, há, acima desta, uma faixa de mata primária, aliás, com boa quantidade de Pau-brasil (Caesalpinea echinata), que colabora para a manutenção de maior riqueza de espécies. Segundo Dorvillé (1996), o domínio de Haemagogus leucocelaenus indica um ambiente de intervenção humana intermediária, com as características principais de uma floresta. Embora ainda dominado por $A$. scapularis, a presença dessa espécie em bom número pode indicar a progressão do ecossistema no sentido da recuperação do ambiente da mata. Talvez uma coleta nos pontos mais conservados e de mata primária do local, viessem a mostrar maior abundância da espécie.

Cantagalo, área de exploração mais recente, apresenta mata secundária em que tanto o número de espécimes coletados quanto o de espécies registradas foram inferiores aos de Engenho do Mato (Tab. I). Pode-se inferir assim, que quanto mais perturbado o ambiente, menor a variedade das espécies. Nesta área, contudo, a proporção de $A$. scapularis é praticamente a mesma que em Engenho do Mato. É mais rica em espécies que Piratininga, e foi a que apresentou maior proporção de A. aegypti, provavelmente em função de ser a que apresenta maior concentração de domicílios próximos.

Vale ressaltar o não aparecimento em Engenho do Mato nem em Cantagalo, de espécies de Anopheles (Kerteszia), comuns nas matas costeiras do leste do Brasil (ARAGÃo 1964), especialmente $A$. (K.) cruzii, que tem segundo DYAR \& KNAB (1909 apud ARAGÃo 1964), a "vertente oceânica da Guanabara" como localidade típica. Esta ausência se explica por necessitarem ambiente melhor conservado (DORVILLÉ 1996), o que confirma o estado de grande influência antrópica nessas áreas. GUIMARÃES et al. (1989) encontraram esta espécie e outras de Anopheles (Kerteszia) no Parque Nacional de Serra dos Órgãos.

O menor número de espécies foi encontrado em Piratininga. Além de ser área de restinga, o local é o mais urbanizado dos três pontos de coleta, o que é um diferencial a mais na interpretação dos resultados. Não bastasse tais diferenças, o ponto exato de coleta era menos sombreado, o que pode ter contribuído para menor ataque de mosquitos no horário da tarde. Somente as espécies melhor adaptadas a 
áreas abertas e mais urbanizadas, como as de Aedes e de Culex e em menor grau, Limatus durhami, são encontradas. Até a década de 60 área malarígena, Piratininga apresentou e ainda nos dias de hoje apresenta o vetor Anopheles aquasalis, como em regiões próximas no Estado do Rio de Janeiro (FLORES-MENDOZA \& LOURENÇO-DE-OLIVEIRA 1996). O anofelino se cria em água salobra, abundante nessa área por ser próxima ao mar e com sistema lagunar ligado a este. A ocorrência deve-se em grande parte também ao fato de que em Piratininga, entre as casas, existem terrenos baldios alagáveis que conservam parte da vegetação original e entre esta poças d'água salobra, devido à salinidade do solo. Vale destacar ainda que nessa região, a proporção de Aedes taeniorhynchus - que também se cria em água salobra (SHANNON 1931; CONSOLI et al. 1994) - é bem maior que nas demais, onde constitui mais de $20 \%$ do total de espécimes coletados, sendo que, nas demais áreas, tal participação superou pouco mais de $2 \%$ (Tabs II-IV).

No que tange às correlações entre as variáveis ambientais e a freqüência de mosquitos observada em cada ponto, analisar-se-á primeiro as correlações entre cada variável e freqüência em cada ponto e depois, comparados os resultados entre os pontos.

Esta análise deve levar em conta o tipo de habitat larvar das espécies envolvidas. SHANNON (1931) descreveu o comportamento e tipos de habitat larvais de várias espécies de mosquitos brasileiros e estas informações fazem parte da base de interpretação dos resultados obtidos neste trabalho.

Em todos os pontos a umidade relativa do ar não apresentou correlação significativa com a freqüência observada. Fato oposto ocorreu com os dados de FORATTINI et al. (1968), pois segundo o autor, houve coincidência da maior umidade com o melhor rendimento das coletas. Considera o autor que diferenças regionais podem influir nesta divergência. Revela-se ser assim, no caso deste estudo, devido ao fato de não ter havido grande variação nesta variável ao longo do período estudado (Tab. V). Isto não quer dizer que este não é um fator importante para os mosquitos, mas que as médias mensais não variaram na área estudada a ponto de se tornar limitante para as espécies em questão. Em âmbito geográfico mais amplo, a umidade, apresentando uma variação mais significativa, deve mostrar-se mais influente na distribuição espacial e geográfica da família Culicidae. O mesmo vale entretanto, para as variações diárias, que são significativas e influenciaram certamente no momento das coletas. Em todos os três pontos de coleta, o R calculado ficou abaixo de 0,5 e em Cantagalo, próximo a zero (Tab. VI).

$\mathrm{Na}$ tabela $\mathrm{V}$ são demonstrados os dados de umidade relativa durante o período de coleta. Dados estes, mais importantes para a explicação do resultado momentâneo da coleta do que para a explicação do resultado global das coletas mensais, uma vez que este fator apresentou baixa correlação com a freqüência de mosquitos ao longo do período de estudo, mas certamente afeta-os ao longo do dia, quando as variações são maiores e podem influir na atividade.

Já a precipitação se mostrou altamente correlacionada com a freqüência em todos os pontos com valores de $\mathrm{R}$ acima de 0,7 (Tab. VI) e todos com alta significância (Tab. VI). Evidentemente, como todas as espécies de culicídeos dependem de coleções d'água para a postura dos ovos, é de se esperar que a falta 
de chuva se torne fator limitante para as populações (exceto Aedes aegypti), pela redução dos locais de desova, o que se dá no período de outono e principalmente inverno, ocorrendo o contrário nos meses de verão, quando os índices pluviométricos são elevados (Tab. V).

Semelhante ao que ocorre com a precipitação, a temperatura também se mostrou altamente correlacionada com a freqüência nos três pontos de coleta. Este fator torna-se limitante à medida em que baixas temperaturas alteram a atividade dos insetos em geral, particularmente os de regiões quentes, diminuindo seu ritmo de atividade. Este fator contribui para a queda do número de espécimes nas coletas de outono e inverno, em que se apresentam menos ativos. À medida em que se aproxima o verão, o subseqüente aumento de temperatura vem acompanhado dos números mais elevados de capturas nas coletas, caracterizando um ciclo sazonal de atividade perceptível pela população na variação da intensidade dos ataques nas diferentes épocas do ano.

$\mathrm{Na}$ área de Engenho do Mato, temperatura e precipitação apresentam $\mathrm{R}$ praticamente iguais, o que nos leva a concluir que estes fatores têm o mesmo peso na explicação da freqüência observada. Neste local, a existência de espécies que se criam em reservatórios mais perenes como bromélias (caso dos sabetinos) pode ajudar a reduzir o peso da precipitação na análise final, quando comparada à temperatura.

Em Cantagalo, a temperatura apresentou $\mathrm{R}$ maior que o da precipitação. É explicável o resultado, tendo-se em vista que a maior densidade de residências no local propicie um número maior de reservatórios onde poderiam desenvolver-se algumas espécies como Aedes albopictus e Aedes aegypti, presentes na área e capturados quase durante todo o ano, o que fez baixar um pouco o peso deste fator na influência sobre as populações estudadas. Além disso, espécies que se criam em bromélias, como os sabetinos também estão apresentando maior freqüência relativa que nas demais áreas.

Já em Piratininga, o R de precipitação e temperatura, embora altamente correlacionados e significativos, são mais baixos que os apresentados no locais de mata. Vale notar que nesse local, a umidade relativa, embora não significativamente correlacionada, apresentou $\mathrm{R}$ bem maior do que nos outros locais de coleta. Primeiramente, isto pode significar menor dependência de água de chuva para reprodução, não só pela quantidade de residências que apresentam reservatórios potenciais para algumas espécies, como também pela presença de espécies que se criam em água salobra como Anopheles aquasalis e Aedes taeniorhynchus. O primeiro sequer foi registrado nos demais pontos de coleta e o segundo representa em Piratininga mais de $20 \%$ do total de espécimes coletados, o que já era de se esperar. Como água salobra e de poças de maré na área não são fatores limitantes, também não é de surpreender que as chuvas não desempenhem aqui o mesmo papel que na mata. Além do mais FLORES-MENDOZA \& LOURENÇO-DE-OLIVEIRA (1996) afirmam que $A$. aquasalis em Guaraí, na Baixada Fluminense apresentam picos de abundância nos períodos de chuvas moderas e não no de chuvas intensas, o que parece ser o caso em Piratininga (Tab. IV), embora a escassez de dados nos impeça de fazer comparação mais profunda. Já a temperatura, apresenta uma dinâmica diferente na restinga do que aparenta na mata. Os dados mostram apenas a tempe- 
ratura média da região durante os meses de coleta. Não se sabe de modo preciso o que ocorre em termos de variação diária de temperatura. Sabe-se entretanto, que na restinga as variações diárias são maiores pois trata-se de local quase todo descampado, a sendo a temperatura à tarde sempre mais elevada em Piratininga, pois não conta com a cobertura vegetal. Em função disso, é de se esperar que a temperatura no microambiente de coleta fosse sempre um pouco mais elevada pelo rápido aquecimento, que os dos demais pontos que não aqueciam tão rapidamente. Isto poderia estar proporcionando aos insetos melhores condições ambientais de atividade que nas outras áreas no mesmo período. Daí a menor correlação detectada que nos outros pontos. Entretanto à noite, o desaquecimento também é muito mais rápido e drástico, causando uma brusca queda de temperatura não observada nos locais de mata. Isto podia ser notado nas coletas quando, da forma mais repentina, o ataque a certa hora cessava quase instantaneamente.

De modo geral, percebe-se que os meses mais quentes (novembro -fevereiro) apresentam maior número de espécies coletadas pois são poucas as que como Aedes scapularis, Aedes albopictus e alguns sabetinos ocorrem ao longo de todo o ano mesmo com baixa freqüência. Isto pode ser devido principalmente à temperatura, que eleva o nível de atividade geral e acelera o mecanismo reprodutivo e à precipitação que forma os criadouros principalmente do Aedes scapularis que foi predominante nas coletas, de Aedes taeniorhynchus e Culex nigripalpus, o que confere com BoIKE (1963). As espécies que se criam em reservatórios perenes, mantiveram-se mais ou menos regulares durante $\mathrm{o}$ ano, não apresentando um pico demasiadamente pronunciado no meses quentes e chuvosos. Estes resultados conferem com os de DAVIS (1945a), que demonstrou a importância do ciclo anual de temperatura e umidade relativa na abundância das espécies de Culicidae notando a dependência dos Culicini das águas de chuva para a reprodução e conseqüente aumento de densidade. DE KRUIJF et al. (1973) estabeleceram o mecanismo pelo qual Aedes scapularis se aproveita do período de chuvas intercalado com dias secos para a reprodução, e de como depende desses períodos para o aumento numérico. GUIMARÃES \& ARLÉ (1984) e LOURENÇO-DEOLIVEIRA et al. (1985), em trabalhos na Serra dos Órgãos e em Jacarepaguá respectivamente encontraram resultados semelhantes, tendo a precipitação e temperatura papel de destaque. Não foi constatada grande correlação entre a variação mensal de umidade relativa e a variação mensal das freqüências das espécies como ocorreu na percepção de GUIMARÃES \& ARLÉ (1984) na Serra dos Órgãos. Deve-se levar em conta, que nas coletas de GUIMARÃES \& ARLÉ (1984) a maioria dos espécimes foi de sabetinos e em ambiente de mata mais preservada e fechada. Além disso, Aedes scapularis teve presença muito menos marcante do que na presente pesquisa. LOURENÇO-DE-OLIVEIRA et al. (1985) destacou as chuvas como o principal fator regulador da densidade populacional dos mosquitos na área de Jacarepaguá, apresentando resultados mais concordantes com os observados nesta pesquisa.

Todos esses dados reforçam a noção de que as espécies que se criam em água de poças no solo são mais dependentes do ciclo das chuvas, enquanto as que se criam em reservatórios permanentes são mais dependentes da temperatura e umidade. Em locais em que esta última varie pouco em níveis que sejam favoráveis, não apresentará grande influência na flutuação da densidade populacional. 
Algumas espécies coletadas são veiculadoras de organismos patogênicos do homem, como Aedes aegypti e A. albopictus, que transmitem os vírus de dengue e de febre amarela e Haemagogus leucocelaenus que é transmissor do vírus da febre amarela no ciclo silvestre; Culex quinquefasciatus que é transmissor primário da Wuchereria bancrofti, agente etiológico da filariose bancroftiana e Anopheles aquasalis, um dos mais eficientes transmissores do Plasmodium causador da malária no Estado (COUTINHO 1946b, 1947; CARVALHO \& RACHOU 1951; FERREIRA 1964), mostrando inclusive, bastante intradomiciliaridade no bairro de Itaipu, próximo a Piratininga (CouTinHo 1946a).

Aedes scapularis e Aedes taeniorhynchus, foram apontados por LABARTHE et al. (1998) como os principais vetores de Dirofilaria immitis (dirofilariose canina) na cidade de Niterói, seguidos de Culex quinquefasciatus considerado de fraca eficiênca vetorial por LOWRIE (1991) e Culex declarator. LOURENÇO-DE-OLIVEIRA \& DEANE (1995) já haviam detectado a presença de larvas presumivelmente desse nematóide, em uma fêmea de Aedes scapularis e em uma outra de Aedes taeniorhychus coletados em Jacarepaguá, assinalando que cerca de $10 \%$ dos cães apresentam microfilaremia de $D$. immitis naquela região. Aedes taenirhynchus é um dos vetores de dirofilariose com maior índice de infestação na Flórida (EUA), segundo trabalho de PARKER (1993).

A dirofilariose caracteriza-se pela presença do nematóide nas artérias pulmonares e ventrículo direito dos canídeos - hóspedeiros naturais - enquanto costuma produzir lesões no pulmão de humanos infectados (Dra. Norma Labarthe, Universidade Federal Fluminense, com. pess.). Como essa doença afeta em Niterói $24,46 \%$ dos cães (LABARTHE et al. 1997), é coerente esperar que casos humanos existam, não sendo detectados devido provavelmente ao desconhecimento da doença por parte do sistema público de saúde até em virtude do fato das pesquisas acerca do assunto na área serem recentes.

Anopheles aquasalis, dependendo da abundância que alcançar, pode se constituir num risco a mais, tendo em vista a possibilidade de imigração de pessoas infectadas em outras áreas do país, como aconteceu em 1997, ano em que se registraram alguns casos de malária em Niterói e em Maricá, constatados posteriormente como alóctones.

As demais espécies figuram como sendo de menor importância na transmissão de doenças, sendo em sua maioria, potenciais transmissores de diversos tipos de arboviroses (CONSOLI \& LOURENÇO-DE-OLIVEIRA 1994).

Fica claro que os riscos epidemiológicos a que estão submetidos os habitantes de Niterói - em particular os da área estudada -, não são desprezíveis, em virtude do crescente aumento da população na região oceânica da cidade. Tendo em vista que Aedes scapularis tem apresentado tendência à domiciliação (FORATTINI 1961; FORATTINI et al. 1978b, 1987b) e apresenta notável antropofilia no intradomicílio (FORATTINI et al. 1987a), tais riscos são ainda mais potencializados. Aedes scapularis e Culex sp. foram relacionados por FoRATTINI et al. (1987a) à transmissão de encefalite por vírus no Vale do Ribeira no Estado de São Paulo nos anos de 1975/76. Tal capacidade vetora e domiciliação foi ratificada mais tarde pelo mesmo autor (FORATTINI et al. 1995). 
Cabe ressaltar a presença de Aedes albopictus, que pode habitar tanto o ambiente rural como o urbano, podendo ser vetor do vírus da febre amarela urbana, pois apresenta nítida preferência por sangue humano em detrimento ao de cães ou gatos (LABARTHE et al. 1998). Esta espécie é também eficiente vetor da dirofilaria no Japão (KONISHI 1989a,b) e transmissor do vírus da dengue. Na região investigada há transmissão dessas doenças e A. albopictus é mais um vetor potencial que deve atrair a atenção das autoridades.

A julgar pelos resultados deste trabalho, faz-se necessário, na região estudada, especificamente o controle intradomiciliar durante todo o ano, posto que Aedes aegypti e Culex quinquefasciatus são muito dependentes do ambiente domiciliar e aí se encontram durante todo o ano (SHANNON 1931) e o combate extradomicilar durante o período de novembro a março, quando os níveis populacionais dos mosquitos da região atingem picos que provocam grande incômodo e colocam em risco a saúde da população.

Na região da lagoa de Piratininga em particular, o combate com Bacillus thuringiensis israelensis deve ser questionado, tendo em vista a constatação de grande quantidade de peixes larvófagos aí existentes, que asseguram provavelmente um controle biológico eficiente. Além do mais, existem na área terrenos baldios que abrigam criadouros mais importantes e protegidos que não estão sendo tratados. Atenção deve ser dada também aos locais pedregosos próximos à faixa das marés, onde se formam criadouros de Aedes taeniorhynchus, que, pelo que foi mostrado até agora, tem importância vetorial nesse bairro.

AGRADECIMENTOS. Ao Dr. Darcílio Fernandes Baptista (Instituto Oswaldo Cruz), pelo empréstimo do programa estatístico e pela ajuda na utilização do mesmo; Dras Denise Pamplona; Valéria Cid Maia, MsC. Carlos José Einicker Lamas, todos do Museu Nacional, pela revisão do texto; Dra. Norma Vollmer Labarthe (Universidade Federal Fluminense) pelas observações pertinentes e informações que tanto ajudaram no desenvolvimento da análise dos dados; Dr. Francisco Nepomuceno (Petrobrás) pela ajuda na elaboração dos gráficos e tabelas e a $\mathrm{MsC}$. Monique de Albuquerque Motta (Instituto Oswaldo Cruz), pela identificação dos sabetíneos.

\section{REFERÊNCIAS BIBLIOGRÁFICAS}

ANDRADE, R.M. 1953. Observações hidrobiológicas do Anopheles tarsimaculatus: I - Relações com alguns organismos planctônicos. Rev. Bras. Malariol. Doenças Trop., Rio de janeiro, 5 (1): 95-107. AragÃo, M.B. 1964. Distribuição geográfica e abundância das espécies de Anopheles (Kerteszia) (Diptera: Culicidae). Rev. Bras. Malariol. Doenças Trop., Rio de janeiro, 16: 73-109.

AraúJo, D.S.D. \& A.M.N. VilaÇA. 1981. Avaliação da cobertura vegetal remanescente de Itaipu, p. 26-46. In: L.M. Kneip; L. PAllestrini \& L. Fausto (Eds). Pesquisas arqueológicas no litoral de Itaipu. Rio de Janeiro, Luna, 174p.

Barroso, L.V.; L.F.F. Silva \& B.A. Knoppers. 1993. Diagnóstico ambiental do sistema lagunar de Piratininga-Itaipu, Niterói/RJ. Parte I: Fisiografia e sócio-economia. Serra Negra, São Paulo. Proc. III Simpósio Ecossistemas da Costa Brasileira, Rio de Janeiro, p. 1-12.

Belkin, J.N.; R.X. Schick \& S.J. Heinemann. 1971. Mosquitoes originally described from Brazil. Contrib. Amer. Entomol. Inst. 7: 1-64.

BOIKE, A.H. 1963. Observations on Culex nigripalpus Theobald in a typical hammock area of north central Florida. Mosq. News 23 (4): 345-348. 
Bourroul, C. 1904. Mosquitos do Brasil. Tese não publicada, Faculdade de Medicina da Bahia, 78p. Carvalho, F.F. \& R.G. Rachou. 1951. Considerações sobre a malária no Estado do Rio de Janeiro, com especial referência ao Vale do Piraí. Rev. Bras. Malariol. Doenças Trop., Rio de Janeiro, 3 (3): 473-487.

CAusey, O.R.; H.W. Kumm \& H.W. LAemmerT. 1950. Dispersion of forest mosquitoes in Brazil: further studies. Amer. Jour. Trop. Med. Hyg. 30: 301-312.

Consoli, R.A.G.B. \& R. Lourenço-DE-Oliveira. 1994. Principais Mosquitos de Importância Sanitária no Brasil. Ed. Rio de Janeiro, Fiocruz, 228p.

CoutinHo, J.O. 1942. Contribuição ao estudo da transmissão da malária no Distrito Federal, Brasil. Rev. Paul. Med., São Paulo, 21 (3): 1-163.

- 1946a. Distribuição geográfica dos anofelinos do Estado do Rio de Janeiro. Arq. Hig. Saúde Públ. São Paulo 11 (29): 439-457.

- 1946b. Contribuição ao estudo da transmissão da malária no Distrito federal. Anopheles darlingi na baixada fluminense. Rev. Paul. Med., São Paulo, 29 (2): 121-122.

-1946c. Observações sobre a biologia de Anopheles darlingi na baixada fluminense, Estado do Rio de Janeiro. Rev. Paul. Med., São Paulo, 29 (3): 202-205.

- 1946d. Anofelinas do Rio de Janeiro, Distrito Federal, com referência à transmissão da malária. Rev. Paul. Med., São Paulo, 29 (4): 284-285.

- 1947. Contribuição para o estudo da distribuição geográfica dos anofelinos do Brasil. Rev. Clin. São Paulo, São Paulo, 21 (3-4): 28-32.

COUTINHO J.O. \& I. RiCCIARDI. 1945. Contribuição para o estudo dos vetores de malária no Brasil. Anopheles darlingi em Campos, no Estado do Rio de janeiro. Mem. Inst. Oswaldo Cruz 42 (1): 262-280.

Cruz, O.G. 1901. Contribuição ao estudo dos culicídeos do Estado do Rio de Janeiro. Bras-Med., Rio de Janeiro, 15 (43): 423-426.

D^vIS, D.E. 1944 a. A comparison of mosquitoes captured with an avian bait at different vegetational levels. Rev. Entomol., Rio de Janeiro, 15 (1-2): 209-215.

- 1944b. Larval habitats of some brazilian mosquitoes. Rev. Entomol., Rio de Janeiro, 15 (1-2): 221-235.

- 1945a. The annual cycle of plants, mosquitoes, birds and mammals in two brazilian forests. Ecol. Monogr. 15: 243-295.

. 1945b. A comparison of mosquitoes captured with avian bait and human bait. Proc. Entomol. Soc. Wash. 47: 252-256.

DEANE, L.M. 1951. Hábitos dos adultos de Culex fatigans. Rev. Serv. Espec. Saúde Púb., Rio de Janeiro, 4 (2): 423-464.

DE Kruisf, H.A.M.; J.P. WoOdall \& A.T. TANG. 1973. The influence of rainfall and its pattern on mosquito (Diptera) populations in Brazil. Bull. Entomol. Res. 63: 327-333.

DORVILLÉ, L.F.M. 1996. Mosquitoes as bioindicators of forest degradation in southeastern Brazil, a statistical evaluation of published data in the literature. Stud. Neotrop. Fauna Environ. 31: 68-78.

DRM (Departamento de Recursos Minerais). 1981. Projeto carta geológica - Bloco Baía de Guanabara. Folhas: Baía de Guanabara, Itaboraí, Saquarema, Maricá. Relatório final. Niterói, DRM, Vol. 1, 219p.

EcP (Engenheiros Consultores Projetistas). 1979. Relatório de Impacto sobre o meio ambiente Plano Estrutural de Itaipu. Rio de Janeiro, Vols 1 e 2, 347p. e 470p.

Ferreira, E. 1964. Distribuição geográfica dos anofelinos no Brasil e sua relação com o estado atual da erradicação da malária. Rev. Bras. Malariol. Doenças Trop., Rio de Janeiro, 16: 329-348.

Flores-Mendozı, C. \& R. Lourenço-de-OliveirA. 1996. Bionomics of Anopheles aquasalis Curry, 1932, in Guaraí, State of Rio de Janeiro, Southeastern Brazil - I. Seazonal distribution and parity rates. Mem. Inst. Oswaldo Cruz 91 (3): 265-270.

ForatTini, O.P. 1961. Some data on the domesticity of Aedes scapularis (Rondani) in São Paulo, Brazil. Mosq. News 21 (4): 295-296. 
1965. Entomologia Médica. \. Paulo, Edusp, Vols 2 e 3, 506p. e 416p.

ForATtINI, O.P.; O.S. LOPES \& E.X. RABELLO. 1968. Investigações sobre o comportamento de formas adultas de mosquitos silvestres no Estado de São Paulo. Rev. Saúde Públ., São Paulo, 2 (2): 111-173.

Forattini, O.P.; A.C. Gomes; E.A.B. Galati; E.X. Rabello \& L.B. Iversson. 1978a. Estudos ecológicos sobre mosquitos Culicidae no sistema da Serra do Mar, Brasil. 1 - Observações no ambiente extradomicilliar. Rev. Saúde Públ., São Paulo, 12: 297-325.

1978b. Estudos ecológicos sobre mosquitos Culicidae no sistema da Serra do Mar, Brasil. 2 - Observações no ambiente domiciliar. Rev. Saúde Públ., São Paulo, 12: 476-496.

Forattini, O.P.; A.C. Gomes; D. NATAL; I. Kakitani \& D. MarUCCI. 1987a. Preferências alimentares de mosquitos Culicidae no Vale do Ribeira, São Paulo, Brasil. Rev. Saúde Públ., São Paulo, 21 (3): $171-187$.

- 1987b. Freqüência domiciliar e endofilia de mosquitos Culicidae no Vale do Ribeira, São Paulo, Brasil. Rev. Saúde Públ., São Paulo, 21 (3): 188-192.

Forattini, O.P.; I. Kakitani; E. Massad; D. MarucCl. 1995. Studies on mosquitoes (Diptera: Culicidae) and antropic environment. 9-Synantropy and epidemiological vector role of Aedes scapularis in South-eastern Brazil. Rev. Saúde Públ., São Paulo, 29 (3): 199-207.

Goeldi, A.E. 1905. Os mosquitos no Pará. Mem. Mus. Paraense Hist. Nat. Ethnogr. 4: 1-154p.

Guimarães, A.E. \& M. Arlé. 1984. Mosquitos no Parque Nacional da Serra dos Órgãos, Estado do Rio de Janeiro, Brasil. I. Distribuição estacional. Mem. Inst. Oswaldo Cruz 79: 309-323.

Guimarães, A.E.; M. Arlé \& R.M.N. Machado. 1985. Mosquitos no Parque Nacional da Serra dos Órgãos, Estado do Rio de Janeiro, Brasil. II. Distribuição vertical. Mem. Inst. Oswaldo Cruz 80: 171-185.

GuimarÃES, A.E. \& V.M.N. Victório. 1986. Mosquitos no Parque Nacional da Serra dos Órgãos, Estado do Rio de Janeiro, Brasil. III. Preferência horária para hematofagia. Mem. Inst. Oswaldo Cruz 81 (1): 93-103.

Guimarães, A.E.; M.A. Motta; M. Arlé; R.M.N. Machado \& L.D. Gonçalves. 1989. Bionomia de mosquitos (Diptera, Culicidae) em áreas da Mata Atlântica no município de Itaguai, Estado do Rio de Janeiro, Brasil. Mem. Inst. Oswaldo Cruz 84 (Supl. 4): 243-254.

KÖEPPEN, W. 1948. Climatologia: com un estudio de los climas de la tierra. México, Fondo Cult. Economica, $478 \mathrm{p}$.

KonISHI, E. 1989a. Culex tritaeniorhynchus and Aedes scapularis (Diptera: Culicidae) as natural vectors of Dirofilaria immitis (Spirurida: Filariidae) in Miki City, Japan. Jour. Med. Entomol. 26 (4): 294-300.

-1989b. Susceptibility of Aedes albopictus and Culex tritaeniorhynchus (Diptera: Culicidae) collected in Miki City, Japan, to Dirofilaria immitis (Spirurida: Filariidae). Jour. Med. Entomol. 26 (5): 420-424.

Labarthe, N.; N. Almosny; J. Guerrero \& A.M. Duque-Araújo. 1997. Description of the occurrence of canine Dirofilariasis in the state of Rio de Janeiro, Brazil. Mem. Inst. Oswaldo Cruz 92: 47-51.

Labarthe, N.; M.L. Serrão; Y.F. Melo; S.J. Oliveira \& R. Lourenço-De-Oliveira. 1998. Mosquito frequency and feeding habits in na enzootic canine dirofilariasis area in Niterói, State of Rio de Janeiro, Brazil. Mem. Inst. Oswaldo Cruz 93 (2): 145-154.

LAMEgo, A.R. 1945. Ciclo evolutivo das Lagunas Fluminenses. Bol. DNPM 118, Rio de Janeiro: 1-39.

LANE, J. 1953. Neotropical Culicidae. Univ. São Paulo. São Paulo, Vols 1 e 2, 1112 p.

Lane, J.\& N.L. Cerqueira. 1942. Os Sabetíneos da América (Diptera: Culicidae). Arq. Zool. Est. São Paulo 3: 473- 849 .

Lourenço-DE-Oliveira, R. 1984. Alguns aspectos da ecologia dos mosquitos (Diptera, Culicidae) de uma área de planície (Granjas Calábria), em Jacarepaguá, Rio de Janeiro, I. Freqüência comparativa das espécies em diferentes ambientes e métodos de coleta. Mem. Inst. Oswaldo Cruz 79 (4): 479-490.

Lourenço-De-Oliveira, R. \& L.M. Deane. 1995. Presumed Dirofilaria immitis Infections in wild 
Wild-Caught Aedes taeniorhynchus and Aedes scapularis in Rio de Janeiro, Brazil. Mem. Inst. Oswaldo Cruz 90 (3): 387-388.

Lourenço-de-Oliveira, R. \& R. Hevden. 1986. Alguns aspectos da ecologia dos mosquitos (Diptera: Culicidae) de uma área de planície (Granjas Calábria), em Jacarepaguá, Rio de Janeiro. IV. Preferências alimentares quanto ao hospedeiro e freqüência domiciliar. Mem. Inst. Oswaldo Cruz 81 (1): $15-27$.

LOURENÇO-DE-Oliveira, R. \& T.F. Silva. 1985. Alguns aspectos da ecologia dos mosquitos (Diptera: Culicidae) de uma área de planície (Granjas Calábria), em Jacarepaguá, Rio de Janeiro. III. Preferência horária das fềmeas para o hematofagismo. Mem. Inst. Oswaldo Cruz 80 (2): 195-201. LOURENÇO-DE-Oliveira, R.; T.F. Silva \& R. HEYdEN. 1985. Alguns aspectos da ecologia dos mosquitos (Diptera: Culicidae) de uma área de planície (Granjas Calábria), em Jacarepaguá, Rio de Janeiro. II. Frequiência mensal e no ciclo lunar. Mem. Inst. Oswaldo Cruz 80 (2): 123-133.

Lowrie, R.C. 1991. Poor vector efficiency of Culex quinquefasciatus following inffection with Dirofilaria immitis. Jour. Amer. Mosq. Control Assoc. 7 (1): 30-36.

MME-DNAEE. 1981. Inventário das estações pluviométricas. Brasília, Ministério das Minas e Energia, Departamento Nacional de Águas e Energia Elétrica.

PARKER, B.M. 1993. Variation in mosquito (Diptera: Culicidae) relative abundance and Dirofilaria immitis (Nematoda: Filarioidea) vector potencial in coastal north Carolina. Jour. Med. Entomol. 30 (2): 436-442.

Rachou, R.G.; M.M. Lima; J.A. Ferreira Neto \& C.M. Martins. 1958. Alguns dados sobre o comportamento de mosquitos de Ponta Grossa (Florianópolis, Santa Catarina). Rev. Bras. Malariol. Doenças Trop., Rio de Janeiro, 10: 417-427.

ShanNon, R.C. 1931. The environment and behaviour of some brazilian mosquitoes. Proc. Entomol. Soc. Wash. 33: 1-27.

WiLLIAMS, C.B. 1937. The use of logarithims in the interpretations of certain entomological problems.

Ann. Appl. Biol. 24: 404-414.

Recebido em 29.VI.2000; aceito em 08.VI. 2001. 